\title{
Differential serostatus of Epstein-Barr virus in Iranian MS patients with various clinical patterns
}

\author{
Bahareh Laribi ${ }^{1}$, Mehdi Shekarabi*2, Amir Hassan Zarnani ${ }^{3}$, Majid Ghaffarpour ${ }^{4}$, Mohsen Marzban $^{5}$
}

Published: 27 Nov 2018

\section{Abstract}

Background: Epidemiological evidence suggests a role of Epstein-Barr virus (EBV) in triggering the pathogenesis of Multiple Sclerosis (MS). The aim of this study was to assess the EBV-specific antibodies in MS patients with various clinical patterns and their association with the production of IFN- $\gamma$, IL-12, and IL-4 cytokines compared with healthy individuals.

Methods: We measured EBNA-1 IgG, VCA IgG, and production of IFN- $\gamma$, IL-12 and IL-4 cytokines in patients with different clinical patterns and healthy controls using ELISA method.

Results: There was a higher titer of anti-EBV antibodies in MS patients compared to healthy controls. SPMS patients generated higher EBNA-1 levels than those with RRMS and PPMS patients whereas; the level of VCA IgG was higher in the RRMS patients than PPMS. In PPMS patients, a significant increase was found in IFN- $\gamma$ and IL-12 cytokines compared to other subtypes, whereas IL-4 cytokine had a decreased level compared to RRMS patients. Higher anti-EBV antibodies are associated with increased IL-12 cytokine in RRMS patients. However, no significant correlation was found between these antibodies and other secreted cytokines.

Conclusion: EBV infection is one of the strong risk factors for MS. Acting on these factors could be useful to decrease the incidence and disease exacerbation of MS. Study of the antibody levels to EBV virus could be useful for evaluating MS risk score in each clinical subtypes.

Keywords: Multiple sclerosis, Epstein-Barr virus, Anti-EBNA-1, Anti-VCA, Cytokines

Conflicts of Interest: None declared

Funding: None

*This work has been published under CC BY-NC-SA 1.0 license.

Copyright $\subseteq$ Iran University of Medical Sciences

Cite this article as: Laribi B, Shekarabi M, Zarnani AH, Ghaffarpour M, Marzban M. Differential serostatus of Epstein-Barr virus in Iranian MS patients with various clinical patterns. Med J Islam Repub Iran. 2018 (27 Nov);32:118. https://doi.org/10.14196/mjiri.32.118

\section{Introduction}

Multiple sclerosis (MS) is a chronic neurological disorder of white matter of the central nervous system (CNS) which affects the sensory, motor, cognitive, and even autonomic CNS functions (1). The cause of MS is complex and multifactorial. It is likely an interaction between genetic and environmental factors which contributes to disease

\footnotetext{
Corresponding author: Dr Mehdi Shekarabi, Shekarabi.m@iums.ac.ir
}

1. Department of Immunology, School of Medicine, Tehran University of Medical Sciences, Tehran, Iran

2. Department of Immunology, School of Medicine, Iran University of Medical Sciences, Tehran, Iran

3. Nanobiotechnology Research Center, Avicenna Research Institute, ACECR, Tehran, Iran

4. Sina MS Research Center, Neuroscience Institute, Tehran University of Medical Sciences, Tehran, Iran

5. Department of Neurosciences, Tehran University of Medical Sciences, Tehran, Iran pathogenesis (2). Among studies investigating environmental risk factors, several Human Herpes Viruses (HHVs) in particular Epstein-Barr virus (EBV) have been linked to MS development. Recent results showed that EBV represents the most association with the MS disease $(3,4)$. Immunological and epidemiological evidences suggest that

\section{$\uparrow$ What is "already known” in this topic:}

Immunological and epidemiological evidences suggest a role of Epstein Barr virus (EBV) in triggering the pathogenesis of Multiple Sclerosis (MS). Since the virus has capability of cyclic reactivation and providing a consistent antigenic challenge, EBV is very suitable trigger of chronic inflammatory state and disease exacerbation in MS.

\section{$\rightarrow$ What this article adds:}

There was a higher titer of anti EBV antibodies in MS patients compared to healthy controls and pattern of serologic response was different between clinical subtypes of MS. This shows that each subject forms a unique pattern of anti-EBV reactivity which remains stable, at least over the interval of study. 
Epstein-Barr virus is the strongest environmental risk factor among the triggers of MS susceptibility (5). However, the exact mechanisms involved in the interplay of EBV infection and MS are not known (6). EBV is a B-lymphotropic g-herpesvirus which is well known for its ability to establishes a life-long asymptomatic infection in B cells. The virus preferentially infects B lymphocytes through binding to the CD21 receptor and MHC class II as its coreceptor. The initiation of EBV-specific immune control is mediated by dendritic cells cross-presenting EBV antigens from infected $\mathrm{B}$ cells, and then it centers around strong memory $\mathrm{CD}^{+}$and $\mathrm{CD}^{+} \mathrm{T}$-cell responses, whereby the $\mathrm{CD}^{+} \mathrm{T}$ cells maintain EBV-specific Th1 immunity, and both $\mathrm{CD}^{+}$and $\mathrm{CD}^{+} \mathrm{T}$ cells target $\mathrm{EBV}$-infected cells directly (7).

EBV continuously stimulates strong T-cell responses during persistent infection. Molecular mimicry between viral and autoantigens and the Th1-polarizing cytokine milieu of protective antiviral T-cell response could maintain autoreactive $\mathrm{T}$ cells in MS patients (8).

Since the virus has the capability of cyclic reactivation and providing a consistent antigenic challenge to the immune system, EBV is the very suitable trigger of chronic inflammatory states and exacerbation in $\operatorname{MS}(9,10)$. Several diseases are associated with EBV infection such as infectious mononucleosis (IM), many types of malignancies and also some of the autoimmune disorders (11-15).

Sero epidemiologic data indicate that patients with MS have an altered antibody response to EBV, but not to other herpesviruses, compared to healthy individuals (16). The risk of developing MS is increased in individuals previously exposed to EBV and being 2.3-fold greater in subjects with a history of infectious mononucleosis. In addition, the risk of developing MS in seronegative individuals is considerably low (17-19).

A higher anti-EBNA-1 IgG level, an indicator of virus replication, is associated with increased MRI disease activity. However, it is not elucidated whether this effect mediated by fluctuations in the EBV viral load intrinsically or the immune response against EBV reflects disease activity (20). In MS disease, patients are divided into different phenotypes based on clinical grounds with input from imaging and para clinical studies including relapsing-remitting multiple sclerosis (RRMS), secondary progressive multiple sclerosis (SPMS) and primary progressive multiple sclerosis (PPMS) (21).

In some clinical contexts, relapses or exacerbations are followed by periods of partial or complete recovery (remissions). In other cases, symptoms are present all the time and worsening gradually after an initial relapsing course with or without acute exacerbations during the progression (22). Identifying the risk factors that cause MS exacerbations is an important step in control and minimizing this condition. The present study aimed to assess anti-EBNA-1 (IgG) and VCA (IgG) antibody levels and their associations with IFN$\gamma$, IL-12 and IL-4 cytokines production in MS patients with different clinical subtypes and healthy individuals for investigating MS risk score in each clinical subtypes.

\section{Methods}

Patients and control subjects with MS

Sixty-eight MS patients were involved in the study, including 45 Relapsing remitting (RR) MS patients, 13 secondary progressive MS (SPMS) and 10 primary progressive (PP) MS patients. All patients were diagnosed according to the revised McDonald criteria at the MS research center of Imam Khomeini hospital, Tehran (21). The Kurtz Expanded Disability Status Scale (EDSS) (23) was assessed by a trained clinician from 0 to 10 in which the 0 score indicates no disability and 10 indicates death due to MS. The patient group comprised 40 women and 28 men (mean age, 35.3 years; age range, 19-58 years). The research protocol was approved by the Ethics Committee of the Medical University of Iran and all patients gave written informed consent. All Patients were in remission and none of them received immunomodulatory drugs for at least 1 month prior to inclusion. healthy controls (HCs) consisting of 8 men and 12 women (mean age, 30 years; age range, 23-41 years) who had no history of MS or other autoimmune diseases in their families agreed to participate in this research. Blood samples were taken after the signing of an informed consent approved by the local Ethical Committee. None of the patients had been receiving corticosteroids at the time of sample collection.

\section{Serology of EBV}

After blood drawing, samples were centrifuged for 15 min at $180 \mathrm{~g}$ at $20^{\circ} \mathrm{C}$ to collect serum. Serum samples were obtained and analyzed for IgG antibodies against EBV viral capsid antigen (VCA) and nuclear antigen-1 (EBNA-1). Then sera were kept frozen $\left(-70^{\circ} \mathrm{C}\right)$ until further use. Serum samples were measured by enzyme-linked immunosorbent assay (ELISA) method according to instructions of the manufacturer, with a serum dilution of $1: 101$. Accordingly, a reference curve was generated in each assay using four standards of pooled high positive serum samples. AntiEBNA-1 and anti-VCA IgG levels of each sample were expressed in arbitrary units obtained by multiplying concentrations extrapolated from the standard curve to the dilution factor. As recommended by the manufacturer, anti-VCA IgG was considered negative if $<18 \mathrm{U} / \mathrm{ml}$, equivocal if 18 $22 \mathrm{U} / \mathrm{ml}$ and positive if $>22 \mathrm{U} / \mathrm{ml}$. anti-EBNA-1 IgG was considered negative if $<18 \mathrm{U} / \mathrm{ml}$, equivocal if $18-22 \mathrm{U} / \mathrm{ml}$ and positive if $>22 \mathrm{U} / \mathrm{ml}$.

\section{Cell Culture}

For analysis of cytokine concentrations in culture supernatant, peripheral blood mononuclear cells (PBMCs) were isolated from heparinized venous blood by standard FicollHypaque (Biochrom, Germany) density centrifugation. The isolated cells were washed three times in sterile PBS $(\mathrm{pH}$ 7.2) and then $10^{6}$ cells $/ \mathrm{mL}$ were cultured in duplicate within RPMI1640 (Sigma-Aldrich, Germany) supplemented with penicillin $(100 \mathrm{IU} / \mathrm{mL})$ and streptomycin $(100 \mu \mathrm{g} / \mathrm{mL})$, HEPES buffer $100 \mathrm{mM}, 10 \%$ fetal calf serum (Gibco, Germany). Cells were stimulated with phyto hemagglutinin (PHA-L) (Sigma, Germany) at the final concentration of 5 $\mu \mathrm{g} / \mathrm{mL}$. The suspension of $10^{6}$ cells/well was incubated in the 24-well plate (Grinner, Germany), in $5 \% \mathrm{CO}_{2}$, at $37^{\circ} \mathrm{C}$. 
After $72 \mathrm{~h}$, the supernatants (SNs) were collected for cytokine measurements using ELISA method.

\section{Cytokine measurement}

SNs from the above cultures were collected and stored at $-70^{\circ} \mathrm{C}$ until the cytokine measurements. IL-4, IL-12 (BenderMed, Austria) and IFN- $\gamma$ (BenderMed, Austria) were measured by using commercial ELISA kits following the manufacturer's recommendations. The detection limits of the studied cytokines were $7.8 \mathrm{pg} / \mathrm{mL}$ for IL-4, 31.25 $\mathrm{pg} / \mathrm{mL}$ for IL-12, and $1.56 \mathrm{pg} / \mathrm{mL}$ for IFN- $\gamma$.

\section{Statistical analysis}

Data analysis was performed using GraphPad InStat software version 6.07 (Graphpad Software Inc.). Statistical analyses of the comparisons for multiple groups (more than two groups) were performed using one-way ANOVA with multiple comparison post-hoc tests to compare results of ELISA experiments according to the normality of the data as assessed by Kolmogorov-Smirnov/Shapiro-Wilk test. Associations between the anti-EBV antibodies levels and cytokines in MS patients with different clinical patterns and healthy individuals were assessed with the Pearson correlation test. A p-value $<0.05$ was considered significant. The error bars in histogram figures represent standard errors of the mean as indicated.

\section{Ethical considerations}

The study was conformed to the Helsinki declaration and reviewed and approved by the local research committee in the MS research center of Imam Khomeini hospital; written informed consent was obtained from all subjects.

\section{Results}

A total of 88 samples were analyzed in this study. Descriptive and clinical features of MS patients and healthy controls at baseline are given in Table 1. There was no remarkable difference between MS patients and healthy individuals in terms of age and gender distribution. Primary progressive MS patients were older with a higher EDSS score at baseline and reversed female/male ratio. All MS patients showed serologic evidence of previous EBV infection and had at least one of the anti-EBV specific antibodies. Distinct features of IgG response to EBNA-1 and VCA antigens were seen in different clinical patterns of MS.

Detection of EBNA-1 and VCA specific IgG antibodies

Specific IgG antibody against EBNA-1 and VCA were measured in serum. We found that MS patients were more seropositive to EBNA-1 and VCA than healthy controls. In MS patients, anti-EBNA-1 (146.3 \pm 9.26$)$ and anti-VCA $(147.3 \pm 6.39)$ specific $\mathrm{IgG}$ titer were significantly higher in comparison with healthy individuals $(113 \pm 13.38, \mathrm{p}=0.04$ and $89.3 \pm 12.92, \mathrm{p}=0.001$, respectively) (Fig. 1A, B). Analyze of serum levels of anti EBNA-1 and VCA antibody in different clinical MS subtypes showed that SPMS patients generated higher EBNA-1 IgG levels (198.2 \pm 11.26$)$ than those with RRMS $(135.4 \pm 18.09, \mathrm{p}<0.05)$ and PPMS $(128 \pm 13.9)$ but, this was not the case for VCA IgG titer, which was higher in the RRMS patients $(161.4 \pm 8.76)$ than PPMS (110.6 $\pm 5.7, \mathrm{p}<0.05)$ (Fig. 1C, D).

\section{Measurement of IFN- - , IL-12 and IL-4 Cytokines}

To explore the causative role of cellular immune responses in different MS subtypes, we measured the levels of several secreted cytokines related to Th1 and Th2 cells including IFN- $\gamma$, IL-12 and IL-4 in the culture supernatant. Our results showed that concentrations of IFN- $\gamma$, IL-12 and IL-4 were significantly higher in MS patients compared to healthy controls $(\mathrm{p}=0.001, \mathrm{p}=0.002$ and $\mathrm{p}=0.005$, respectively, Fig. 2). In addition, ratios of IFN- $\gamma /$ IL-4 and IL12/IL-4 were higher in MS patients than healthy individuals, while this difference was not statistically significant $(\mathrm{p}>0.05)$.

Based on our cytokine secretion analysis in MS subtypes, we found that PPMS patients have significant increase in the levels of the IFN- $\gamma$ and IL-12 cytokines compared to the RRMS patients $(\mathrm{p}<0.001$ and $\mathrm{p}<0.0001$, respectively), whereas the level of IL-4 cytokine was decreased compared to RRMS patients $(\mathrm{p}<0.001)$. Furthermore, in RRMS subtype, the level of IL-12 cytokine was lower than PPMS subtype $(\mathrm{p}<0.001)$, the level of IFN- $\gamma$ cytokine was also lower than PP subtype $(p<0.001)$, whereas the level of IL-4 cytokine was higher in this group rather than PPMS subtype $(p<0.001)$. Figure 3 represents the results.

\section{Association of anti-EBV antibodies and production of IFN- $y$, IL-12 and IL-4 cytokines}

We further investigated the possible association between the levels of anti-EBV antibodies and IFN- $\gamma$, IL-12 and IL4 cytokines. We found that anti-EBNA-1 and anti-VCA IgG antibodies positively correlated with IL-12 cytokine level in RRMS patients, indicating that the higher antiEBNA-1 and VCA IgG levels are associated with increased IL- 12 cytokine $(\mathrm{p}=0.02, \mathrm{r}=0.27 \& \mathrm{p}=0.04, \mathrm{r}=0.25$ respectively, Fig. 4). However, no significant correlation was found between these antibodies and the levels of IFN- $\gamma$ and IL-4 secreted cytokines.

\begin{tabular}{|c|c|c|c|c|}
\hline \multirow[t]{2}{*}{ Variable } & \multicolumn{4}{|c|}{ Group } \\
\hline & $\operatorname{RRMS}^{1}(\mathrm{n}=45)$ & $\operatorname{SPMS}^{2}(\mathrm{n}=13)$ & $\operatorname{PPMS}^{3}(\mathrm{n}=10)$ & Healthy control $(n=20)$ \\
\hline Age (range), year & $30(19-52)$ & $32(26-43)$ & $44(36-58)$ & $30(23-41)$ \\
\hline Gender (female/male) & $29 / 16$ & $8 / 5$ & $3 / 7$ & $12 / 8$ \\
\hline Disease duration (years) & $2.5(1-6)$ & $5.8(1-19)$ & $7.2(2-20)$ & - \\
\hline $\mathrm{EDSS}^{4}$ (range) & $1.8(0.5-3)$ & $3.6(2.5-4)$ & $4.9(3.5-6.5)$ & - \\
\hline
\end{tabular}


A

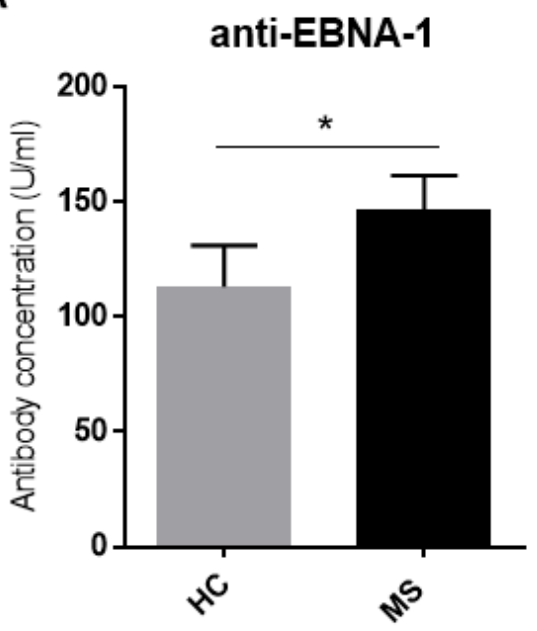

C

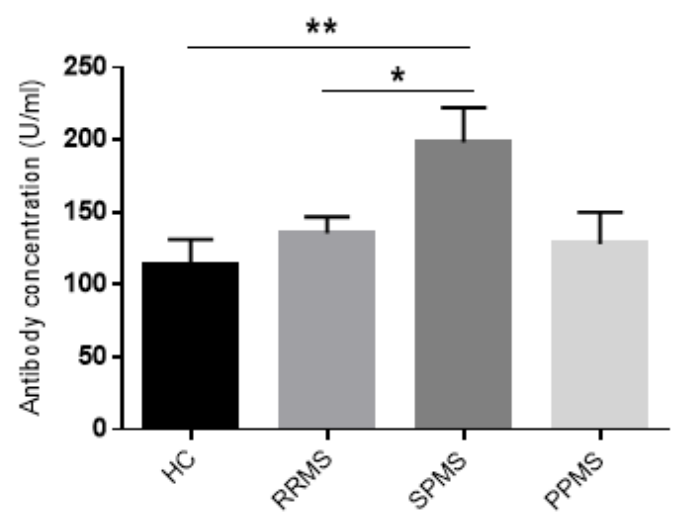

B

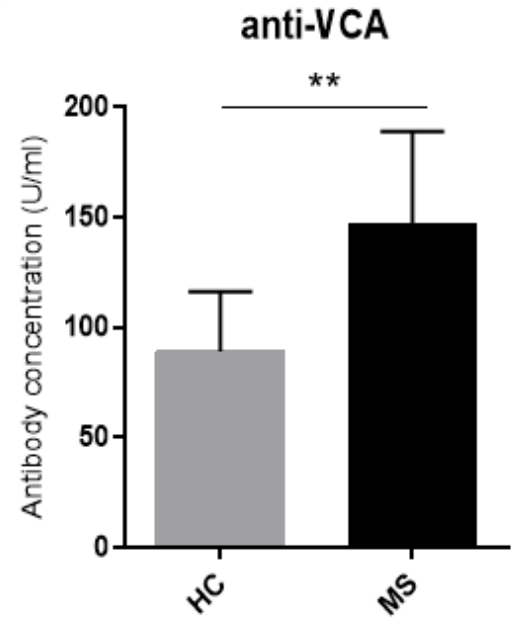

D

anti-VCA

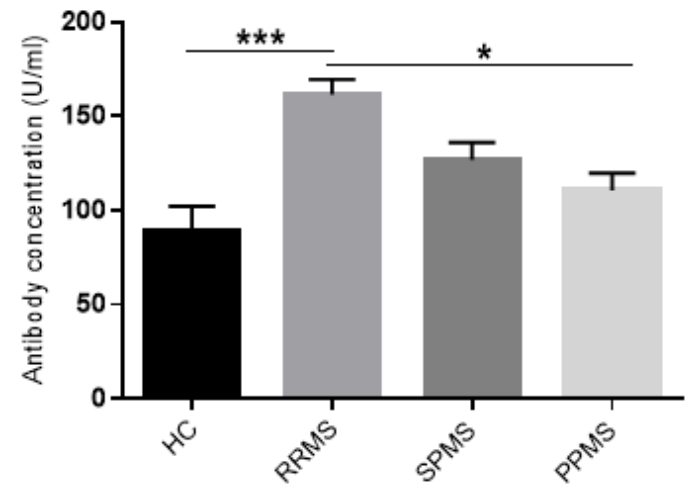

Fig. 1. Specific IgG antibody against EBNA-1 and VCA in MS patients and healthy controls. Specific IgG antibody to EBNA-1 and VCA in MS patients and healthy controls (A, B) and MS patients with different clinical subtypes (C, D). Histogram figures represent mean \pm S.E.M. HC= healthy control; RRMS, relapsing-remitting multiple sclerosis; SPMS, secondary progressive multiple sclerosis; PPMS, primary progressive multiple sclerosis. $* \mathrm{p}<0.05, * * \mathrm{p}<0.001, * * * \mathrm{p}<0.0001$

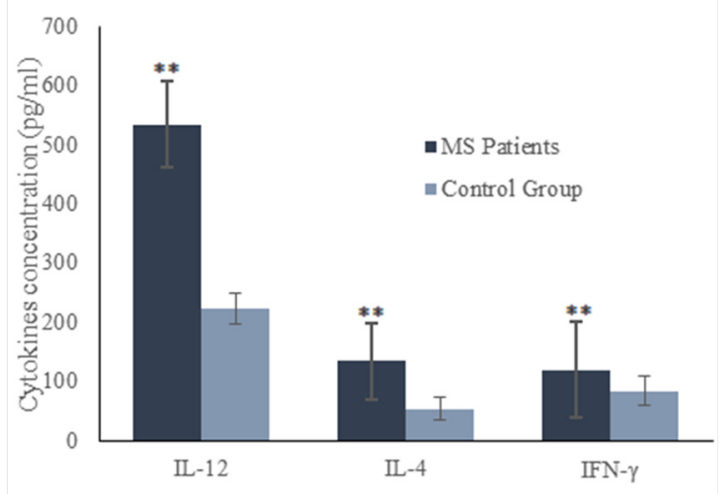

Fig. 2. Concentrations of IFN- $\gamma$, IL-12 and IL-4 cytokines in MS patients and healthy controls. Horizontal lanes indicate mean values. $* * \mathrm{p}<0.001$.

\section{Discussion}

There is a yearly increase in the prevalence of MS in the world $(24,25)$. Moreover, the prevalence of Middle East indicates that the region has more than 350,000 cases and the amount is believed to be rising annually (25). The eti- ology and pathogenesis of MS are still unclear. It is complex and multifactorial. In recent years, the environmental factors include vitamin D deficiency, smoking, lack of sunlight exposure, and infectious agents has been improved as strong risk factors for MS disease, whereas EBV infection is the strongest among them $(5,26)$. 
A

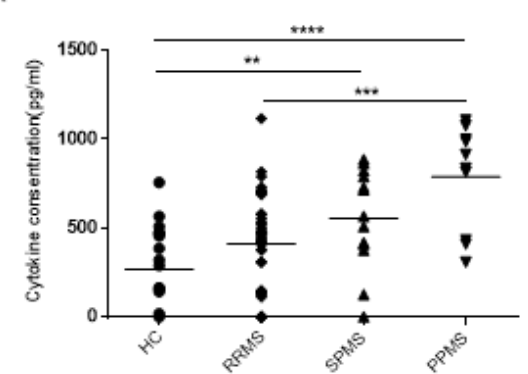

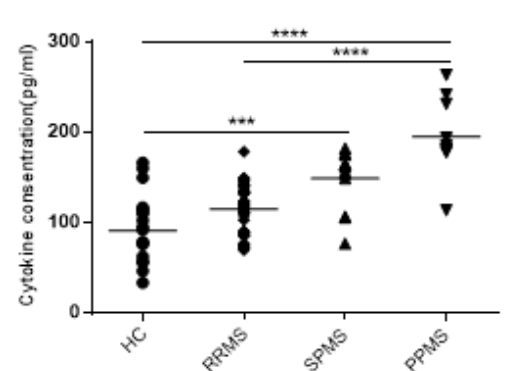

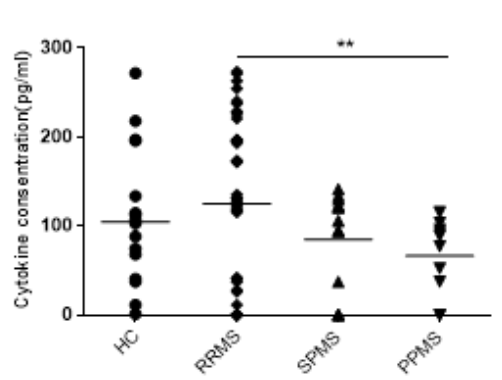

Fig. 3. Concentrations of IFN- $\gamma$, IL-12 and IL-4 cytokines in MS patients with different clinical subtypes and healthy controls. PPMS patients had a significant increase in IFN- $\gamma$ and IL-12 cytokines compared to other subtypes, whereas IL-4 cytokine had a decreased level compared to RRMS patients. in RRMS subtype the levels of IL-12 and IFN- $\gamma$ cytokines were lower than SPMS and PPMS subtypes, whereas the level of IL-4 cytokine was higher compared to PPMS subtype. Horizontal lanes indicate mean values. HC= healthy control; RRMS, relapsing-remitting multiple sclerosis; SPMS, secondary progressive multiple sclerosis; PPMS, primary progressive multiple sclerosis. $* * \mathrm{p}<0.001, * * * \mathrm{p}<0.0001, * * * * \mathrm{p}<0.00001$
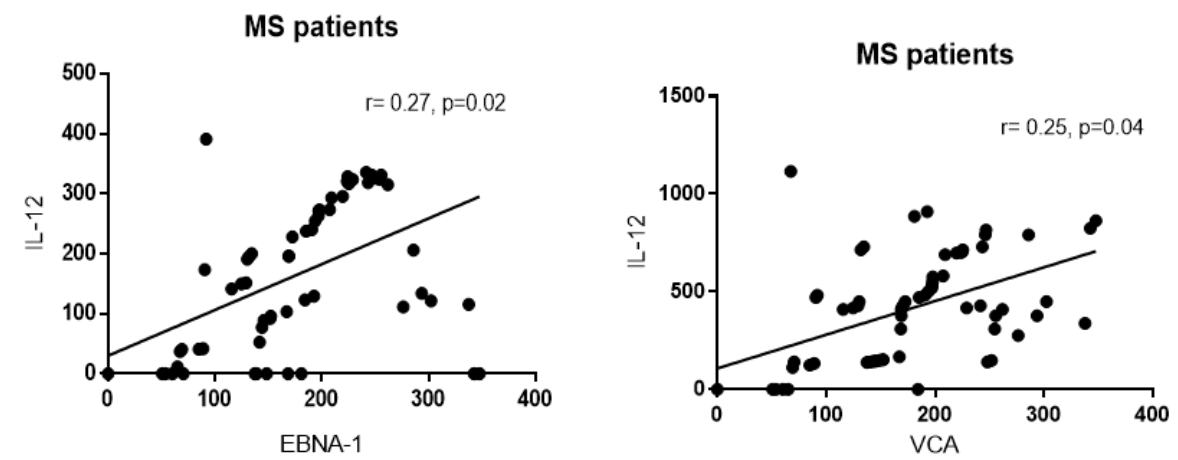

Fig. 4. Correlation between serum levels of anti-EBV antibodies and production of IL-12 cytokine. a positive correlation was found between antiEBNA-1 and VCA antibodies and IL-12 production $(\mathrm{p}=0.02 ; \mathrm{r}=0.27$ and $\mathrm{p}=0.04 ; \mathrm{r}=0.25$, respectively). The correlation coefficient and $\mathrm{p}$-values are given. A p-value $<0.05$ was considered statistically significant.

There are some evidences that EBV reactivation is associated with clinical disease activity in MS, but little is known about the serostatus of EBV in the different clinical subtypes of MS. In this study, the pattern of serologic immune response showed a difference between clinical subtypes, which may imply a distinct immunologic response to primary EBV infection. Here, we demonstrated that the levels of specific anti-EBNA-1 and VCA antibodies were significantly higher in MS patients compared to healthy individuals which are consistent with previous studies (27-32). High levels of EBV antibodies in MS patients could be the result of ongoing inflammatory immune responses and activation state of B cells in MS disease.

Analysis of serum EBV antibody levels in each subtype indicated higher EBNA-1 IgG levels in SPMS patients than other MS subtypes. Whereas, in RRMS patients the levels of IgG specific to VCA was greater than SPMS and PPMS patients. This discrepancy could be the result of the more important role of EBNA-1 antigen in the pathogenesis of MS and might be contributing to disease exacerbation. In the previous study in a large MS/CIS cohort, all MS subjects had evidence of prior EBV infection. Farrell et.al showed that higher titers of EBNA-1 IgG were associated with the development of $\mathrm{Gd}^{+}$lesions on MRI and this elevation in EBNA-1 IgG is independent of VCA IgG titers. In their studies, a higher EBNA-1 IgG titer exhibited an increase in T2 lesion volume and EDSS scale over the study period. They found that EBNA-1 IgG was the only anti- body whose titer was consistently different between subgroups (31). On the contrary, Zivadinov et al. demonstrated that anti-VCA IgG levels were positively correlated with $\mathrm{T} 2$ and $\mathrm{T} 1$ lesion volume (33). This difference may be caused by the variation in detection technique, as Farrell study used the automated Liaison quantitative chemiluminescent in their assays.

EBV continuously stimulates strong T-cell responses during persistent infection. Molecular mimicry between viral and autoantigens and the Th1-polarizing cytokine milieu of protective antiviral T-cell response could maintain autoreactive $\mathrm{T}$ cells in $\mathrm{MS}$ patients (8). In the present study, measurement of cytokine production showed that the levels of IFN- $\gamma$ and IL-12 secreted cytokines in the culture supernatant were significantly higher in MS patients than healthy individuals. Analysis of cytokine secretion in MS subtypes showed that PPMS patients have a significant increase in IFN- $\gamma$ and IL-12 cytokines and a decrease in IL-4 levels compared with other subtypes. IFN- $\gamma$ and IL-12 cytokines induce inflammatory responses. IFN- $\gamma$ has synergic effect on IL-12-mediated Th1 profile differentiation (34). Previous studies indicated that IL-12 secretion considerably increased in mononuclear cells of MS patients $(35,36)$. Ozenci et al. found that even in the absence of high amounts of IL-12, increased expression of its receptor might be augmented in MS (35). IL-12 has the main role in differentiation of T lymphocytes to Th1 phenotype and induces production of IFN- $\gamma$ in these cells (35). In general, MS patients accumulate highly Th1-polarized and EBNA1-targeting T 
cells with less restricted epitope specificity which is compatible with the classical concept of infection associated autoimmunity (8).

In this study, we found a positive correlation between anti-EBV antibodies and IL-12 cytokine in RRMS patients; this result could suggest the role of prior infection with EBV in triggering or perpetuating disease activity in MS. EBV is a prevalent human herpes virus that infects $95-98 \%$ of individuals in the world with distinct ability to infect, activate, and latent persistency in B lymphocytes for the lifetime of the infected individual $(11-13,37)$. There are some hypotheses to explain the failure of immune tolerance by EBV, including molecular mimicry between viral and myelin antigens $(6,37,38)$, EBV-induced expansion of auto-reactive B cells $(38,39)$, induction of heat-shock proteins and super-antigens (3), but evidence that these mechanisms are relevant to MS is not available yet.

There are some environmental factors or conditions that can influence the measurement of cytokine production or EBV antibodies. Our study has limitations with respect to patient numbers and the lack of flow cytometric data, which might preclude detection of small but statistically significant changes.

\section{Conclusion}

To conclude, this study shows that the levels of specific anti-EBNA-1 and VCA antibodies were significantly higher in MS patients compared to healthy individuals and pattern of serologic response was different between clinical subtypes of MS. This suggests that each subject forms a unique pattern of anti-EBV antibody reactivity which remains stable, at least over the interval tested in this study. Detection of anti-EBV antibodies and cytokine measurement in patients may predict disease exacerbations in different clinical subtypes. EBV infection is one of the strong risk factors for MS. Acting on these factors may decrease the incidence and disease exacerbation of MS. Study of the antibody levels to EBV virus might be useful for evaluating MS risk score in each clinical subtypes.

\section{Acknowledgements}

We thank MS patients, healthy individuals for participating in this study, Dr. Shokufeh Sadaghiani for assessing EDSS score and Dr. Rashid Mirzavand for their help and revising the manuscript.

\section{Conflict of Interests}

The authors declare that they have no competing interests.

\section{References}

1. McKay KA, Jahanfar S, Duggan T, Tkachuk S, Tremlett H. Factors associated with onset, relapses or progression in multiple sclerosis: A systematic review. Neurotoxicology. 2016.

2. Belbasis L, Bellou V, Evangelou E, Ioannidis JP, Tzoulaki I. Environmental risk factors and multiple sclerosis: an umbrella review of systematic reviews and meta-analyses. Lancet Neurol. 2015;14(3):263-73.

3. Pender MP. The Essential Role of Epstein-Barr Virus in the Pathogenesis of Multiple Sclerosis. Neuroscientist. 2011;17(4):351-67.

4. Ascherio A, Munger KL. Epstein-barr virus infection and multiple sclerosis: a review. J Neuroimmune Pharmacol. 2010;5(3):271-7.
5. Ascherio A. Environmental factors in multiple sclerosis. Expert Rev Neurother. 2013;13(12 Suppl):3-9.

6. Owens GP, Bennett JL. Trigger, pathogen, or bystander: the complex nexus linking Epstein- Barr virus and multiple sclerosis. Mult. Scler J. 2012;18(9):1204-8

7. Lünemann JD, Kamradt T, Martin R, Münz C. Epstein-Barr virus: environmental trigger of multiple sclerosis? J Virol. 2007;81(13):677784.

8. Lünemann JD, Münz C. Epstein-Barr virus and multiple sclerosis. Curr Neurol Neurosci Rep. 2007;7(3):253-8.

9. Santiago O, Gutierrez J, Sorlozano A, de Dios Luna J, Villegas E, Fernandez O. Relation between Epstein-Barr virus and multiple sclerosis: analytic study of scientific production. Eur J Clin Microbiol Infect Dis. 2010;29(7):857-66.

10. Pakpoor J, Disanto G, Gerber JE, Dobson R, Meier UC, Giovannoni $\mathrm{G}$, et al. The risk of developing multiple sclerosis in individuals seronegative for Epstein-Barr virus: a meta-analysis. Mult Scler. 2013;19(2):162-6.

11. Thorley-Lawson DA. Epstein-Barr virus: exploiting the immune system. Nat Rev Immunol. 2001;1(1):75-82.

12. Salvetti M, Giovannoni G, Aloisi F. Epstein-Barr virus and multiple sclerosis. Curr Opin Neurol. 2009;22(3):201-6.

13. Pender MP. Infection of autoreactive B lymphocytes with EBV, causing chronic autoimmune diseases. Trends Immunol. 2003;24(11):584-8.

14. James JA, Robertson JM. Lupus and Epstein-Barr. Curr Opin Rheumatol. 2012;24(4):383-8.

15. Posnett DN. Herpesviruses and autoimmunity. Curr Opin Investig Drugs. 2008;9(5):505-14.

16. Myhr K-M, Riise T, Barrett-Connor E, Myrmel H, Vedeler C, Grønning M, et al. Altered antibody pattern to Epstein-Barr virus but not to other herpesviruses in multiple sclerosis: a population based casecontrol study from western Norway. J Neurol Neurosurg Psychiatry. 1998;64(4):539-42.

17. Ascherio A, Munger KL. Environmental risk factors for multiple sclerosis. Part I: the role of infection. Ann. Neurol. 2007;61(4):288-99.

18. Thacker EL, Mirzaei F, Ascherio A. Infectious mononucleosis and risk for multiple sclerosis: a meta-analysis. Ann Neurol. 2006;59(3):499 503.

19. Levin LI, Munger KL, O'Reilly EJ, Falk KI, Ascherio A. Primary infection with the Epstein-Barr virus and risk of multiple sclerosis. Ann Neurol. 2010;67(6):824-30.

20. Kvistad S, Myhr KM, Holmoy T, Bakke S, Beiske AG, Bjerve KS, et al. Antibodies to Epstein-Barr virus and MRI disease activity in multiple sclerosis. Mult Scler. 2014;20(14):1833-40.

21. Polman CH, Reingold SC, Banwell B, Clanet M, Cohen JA, Filippi M, et al. Diagnostic criteria for multiple sclerosis: 2010 Revisions to the McDonald criteria. Ann Neurol. 2011;69(2):292-302.

22. Lublin FD, Reingold SC, Cohen JA, Cutter GR, Sorensen PS, Thompson AJ, et al. Defining the clinical course of multiple sclerosis: the 2013 revisions. Neurology. 2014;83(3):278-86.

23. Kurtzke JF. Rating neurologic impairment in multiple sclerosis: an expanded disability status scale (EDSS). Neurology. 1983;33(11):144452.

24. Izadi S. Significant Increase in the Prevalence of Multiple Sclerosis in Iran in 2011. Iran J Basic Med Sci. 2014;39(2):152-3.

25. Al-Hashel J, Besterman AD, Wolfson C. The prevalence of multiple sclerosis in the Middle East. Neuroepidemiology. 2008;31(2):129-37.

26. Wingerchuk DM. Environmental factors in multiple sclerosis: Epstein-Barr virus, vitamin D, and cigarette smoking. Mt Sinai J Med. 2011;78(2):221-30.

27. Sundstrom P, Juto P, Wadell G, Hallmans G, Svenningsson A, Nystrom L, et al. An altered immune response to Epstein-Barr virus in multiple sclerosis: a prospective study. Neurology. 2004;62(12):227782.

28. Buljevac D, van Doornum GJJ, Flach H, Groen J, Osterhaus A, Hop W, et al. Epstein-Barr virus and disease activity in multiple sclerosis. J. Neurol. Neurosurg. Psychiatry. 2005;76(10):1377-81.

29. Larsen PD, Bloomer LC, Bray PF. Epstein-Barr nuclear antigen and viral capsid antigen antibody titers in multiple sclerosis. Neurology. 1985;35(3):435-8.

30. Wagner HJ, Hennig H, Jabs WJ, Siekhaus A, Wessel K, Wandinger KP. Altered prevalence and reactivity of anti-Epstein-Barr virus antibodies in patients with multiple sclerosis. Viral Immunol. 2000;13(4):497-502. 
31. Farrell RA, Antony D, Wall GR, Clark DA, Fisniku L, Swanton J, et al. Humoral immune response to EBV in multiple sclerosis is associated with disease activity on MRI. Neurology. 2009;73(1):32-8.

32. Lindsey JW, Hatfield LM, Vu T. Epstein-Barr virus neutralizing and early antigen antibodies in multiple sclerosis. Eur $\mathrm{J}$ Neurol. 2010;17(10):1263-9.

33. Zivadinov R, Weinstock-Guttman B, Zorzon M, Uxa L, Serafin M, Bosco A, et al. Gene-Environment Interactions Between HLA B7/A2, EBV Antibodies Are Associated With MRI Injury in Multiple Sclerosis. J Neuroimmunol. 2009;209(1):123-30.

34. Haahr S, Hollsberg P. Multiple sclerosis is linked to Epstein-Barr virus infection. Rev Med Virol. 2006;16(5):297-310.

35. Ozenci V, Pashenkov M, Kouwenhoven M, Rinaldi L, Soderstrom M, Link H. IL-12/IL-12R system in multiple sclerosis. J Neuroimmunol. 2001;114(1-2):242-52.

36. Laribi B, Bakhshayesh M, Nourbakhsh S, Ghabaee M, Ghaffarpour M, Shekarabi M, et al. Comparison of Epstein Barr virus antibodies and Tcell cytokines production in patients with multiple sclerosis and healthy individuals. Med J Islam Repub Iran. 2010;24(3):115-25.

37. Pawate S, Sriram S. The role of infections in the pathogenesis and course of multiple sclerosis. Ann Indian Acad Neurol. 2010;13(2):80-6.

38. Chang RA, Miller SD, Longnecker R. Epstein-Barr virus latent membrane protein $2 \mathrm{~A}$ exacerbates experimental autoimmune encephalomyelitis and enhances antigen presentation function. Sci Rep. 2012;2:353.

39. Dunham J, Van Driel N, Eggen BJ, Paul C, A`t Hart B, Laman JD, et al. Analysis of the cross-talk of Epstein-Barr virus-infected B cells with $\mathrm{T}$ cells in the marmoset. Clin Transl Immunol. 2017;6(2):e127. 